\title{
Cortical Regulation of Nociception of the Trigeminal Nucleus Caudalis
}

\author{
Alberto Castro, ${ }^{1 \star}$ Charles Raver, ${ }^{1 \star}$ Ying Li, ${ }^{1}$ @Olivia Uddin, ${ }^{1}$ David Rubin, ${ }^{1}$ Yadong Ji, ${ }^{2}$ Radi Masri, ${ }^{2}$ and $\oplus^{\oplus}$ Asaf Keller $^{1}$ \\ ${ }^{1}$ Department of Anatomy \& Neurobiology, Program in Neuroscience, University of Maryland School of Medicine, Baltimore, Maryland 21201, and \\ ${ }^{2}$ Department of Endodontics, Prosthodontics and Operative Surgery, Baltimore College of Dentistry, Program in Neuroscience, Baltimore, Maryland 21201
}

Pain perception is strongly influenced by descending pathways from "higher" brain centers that regulate the activity of spinal circuits. In addition to the extensively studied descending system originating from the medulla, the neocortex provides dense anatomical projections that directly target neurons in the spinal cord and the spinal trigeminal nucleus caudalis (SpVc). Evidence exists that these corticotrigeminal pathways may modulate the processing of nociceptive inputs by $\mathrm{SpVc}$, and regulate pain perception. We demonstrate here, with anatomical and optogenetic methods, and using both rats and mice (of both sexes), that corticotrigeminal axons densely innervate SpVc, where they target and directly activate inhibitory and excitatory neurons. Electrophysiological recordings reveal that stimulation of primary somatosensory cortex potently suppresses $\mathrm{SpVc}$ responses to noxious stimuli and produces behavioral hypoalgesia. These findings demonstrate that the corticotrigeminal pathway is a potent modulator of nociception and a potential target for interventions to alleviate chronic pain.

Key words: chronic pain; descending modulation; optogenetics; rodent

\section{Significance Statement}

Many chronic pain conditions are resistant to conventional therapy. Promising new approaches to pain management capitalize on the brain's own mechanisms for controlling pain perception. Here we demonstrate that cortical neurons directly innervate the brainstem to drive feedforward inhibition of nociceptive neurons. This corticotrigeminal pathway suppresses the activity of these neurons and produces analgesia. This corticotrigeminal pathway may constitute a therapeutic target for chronic pain.

\section{Introduction}

Pain perception is strongly influenced by cognitive factors, including attentional state, emotional context, attitudes, expectations, hypnotic suggestions, or anesthesia-induced changes in consciousness (Fields, 2000; Villemure and Bushnell, 2002; Bushnell et al., 2013). Cognitive influences on pain perception are attributed to cortical circuits whose descending outputs modulate information processing at spinal and brainstem levels (Apkarian et al., 2005; Tracey and Mantyh, 2007). Therefore, an

\footnotetext{
Received Dec. 21, 2016; revised 0ct. 1, 2017; accepted 0ct. 11, 2017.

Author contributions: A.C., R.M., and A.K. designed research; A.C., C.R., Y.L., O.U., D.R., Y.J., and A.K. performed research; A.C., C.R., Y.L., O.U., Y.J., R.M., and A.K. analyzed data; A.C. and A.K. wrote the paper.

This work was supported by National Institute of Dental \& Craniofacial Research, National Institutes of Health Award R01DE021735 and National Institute of Neurological Disorders and Stroke R01NS069568. The content is solely the responsibility of the authors and does not necessarily represent the official views of the National Institutes of Health.

The authors declare no competing financial interests.

A.C. and C.R. contributed equally to this work.

Correspondence should be addressed to Dr. Asaf Keller, Department of Anatomy \& Neurobiology, Program in Neuroscience, University of Maryland School of Medicine, 655 West Baltimore Street, Baltimore, MD 21201. E-mail: asafkeller@fastmail.us.

DOI:10.1523/JNEUROSCI.3897-16.2017

Copyright $\odot 2017$ the authors $\quad 0270-6474 / 17 / 3711431-10 \$ 15.00 / 0$
}

effective strategy for pain relief, especially in cases of chronic pain, is to engage these descending modulatory systems to suppress pain signals at early stages of processing. Ideally, this should be done where nociceptive afferents transfer signals to secondorder neurons as this could reduce transmission of pain signals to higher brain areas.

The most completely characterized descending pain modulating circuit is the periaqueductal gray-rostroventral medulla system (Dubner and Ren, 1999; Fields, 2000; Heinricher et al., 2009). This system is influenced by forebrain structures, including the amygdala and neocortex, and provides an indirect route for cognitive regulation of pain. In addition to these indirect pathways, the neocortex provides dense anatomical projections that directly target second order neurons in the spinal cord and the trigeminal nuclei. Brodal et al. (1956) provided one of the first descriptions of direct projections from cortical areas, in the cat, to sensory trigeminal nuclei. Subsequent work in cats showed direct inputs from primary somatosensory cortex (SI) (Dunn and Tolbert, 1982) and the second somatosensory cortex (SII) (Tashiro et al., 1983) to the spinal subnucleus caudalis $(\mathrm{SpVc})$, the target of primary nociceptive afferents from the head and neck (Dubner and Ren, 2004). In rats, direct inputs to SpVc 
arise from SI, SII, and from the insula (Gojyo et al., 2002; Noseda et al., 2010; Malmierca et al., 2014; Wang et al., 2015), and the inputs from SI are somotosopically organized (Wise et al., 1979). Efferents from SI and SII in the rat diverge to target overlapping regions in SpVc (Smith et al., 2015). SI projects directly to trigeminal nuclei also in the mouse (Hattox and Nelson, 2007). Some corticotrigeminal axons collateralize in the spinal cord or tectum (Killackey et al., 1989).

That these corticotrigeminal pathways affect sensory processing was demonstrated more than a century ago (Hernandez-Peon and Hagbarth, 1955). Darian-Smith and Yokota (1966) showed that corticotrigeminal inhibitory influences may occur through both presynaptic and postsynaptic mechanisms. Several studies reported that these influences may affect nociceptive processing in trigeminal nuclei, but some of these findings appear to be contradictory. Long-term stimulation of SII, but not of SI, reduced formalin-evoked increases in cFos in $\mathrm{SpVc}$ (Gojyo et al., 2002). However, Malmierca et al. (2012) report that stimulation of either cortical area attenuated the increase in $\mathrm{SpVc}$ firings evoked by capsaicin, and that stimu-

lation of SI, but not SII, reduced the increase in non-noxious responses from surround receptive fields. Corticotrigeminal neurons in the insula exhibited elevated activity in a model of neuropathic pain, and suppressing this activity reduced cFos expression in SpVc and pain behaviors (Wang et al., 2015). One goal of the present study is to address these apparently conflicting findings.

These findings from rat studies lead to two additional questions: (1) Are the effects of cortical stimulation mediated by direct corticotrigeminal inputs, or are they relayed through other subcortical structures? (2) Anatomical data suggest that corticotrigeminal inputs target both excitatory (projection) and inhibitory (local circuit) neurons in the trigeminal complex (Darian-Smith and Yokota, 1966; Furuta et al., 2010). Why, then, is the net effect of cortical stimulation to suppress SpVc activity? Here we test the hypothesis that cortical inputs target local inhibitory neurons to generate feedforward inhibition of trigemino-projection cells. In addition, we test the function of corticotrigeminal inputs in the mouse.

\section{Materials and Methods}

Animals. All animal protocols were approved by the University of Maryland's Institutional Animal Care and Use Committee, and adhered to National Research Council guidelines. To identify GABAergic neurons during in vitro recordings, we used transgenic mice that express GFP under the control of the GAD2 promoter; these mice were developed and characterized by Szabo and collaborators (López-Bendito et al., 2004). We used both male and female GAD-GFP mice for all anatomical and optogenetic experiments. Factorial ANOVA revealed no significant interaction of sex with any measured variable. Therefore, we combined data from both sexes.

We used adult (>100-d-old) Sprague Dawley male rats in all in vivo recording experiments and for the behavioral study.

Recovery surgical procedures. Survival surgery was conducted using aseptic conditions. Surgery was performed with the animal on a thermo- regulated heating pad. Animals were deeply anesthetized (isoflurane $2.5 \%-3 \%$ induction; $1 \%-2 \%$ maintenance) and administered Rimadyl $(5 \mathrm{mg} / \mathrm{kg}$ s.c.). For injection of tracers or viral constructs, and for electrode implantations, animals were placed in a stereotaxic frame and a coordinate system used to guide injections (Paxinos and Franklin, 2004; Paxinos and Watson, 2007).

Cholera toxin subunit B (CTB). Five adult (>100-d-old) GAD-GFP mice were injected with CTB (List Biological Labs). Injections targeted the vibrissae representation of the SI ("barrel cortex"), based on stereotaxic coordinates and using the middle cerebral artery as a landmark. We made pressure injections at depths of $0.8 \mathrm{~mm}$ and $0.7 \mathrm{~mm}, 0.5 \mu \mathrm{l}$ at each injection site, at a rate of $50 \mathrm{nl} / \mathrm{min}$. Three days later, the animals were deeply anesthetized and perfused transcardially with buffer, followed by $4 \%$ PFA. Brains were removed and immersed in the fixative overnight. Sections through the injection site ( $50 \mu \mathrm{m}$ thick) were cut at the coronal plane with a vibratome. Sections through the trigeminal SpVc were cut at $50 \mu \mathrm{m}$ in the horizontal plane.

These sections were processed for double-label immunocytochemistry (Hsu and Soban, 1982) with antibodies against CTB (goat anti-CTB; List Biological catalog \#7032A6 RRID:AB_2313637; 1:20,000) and GFP (chicken anti-GFP; Aves Labs; catalog \#GFP-1020 RRID:AB_10000240; $1: 10,000)$. Sections were incubated first in anti-CTB for $\sim 70 \mathrm{~h}$ at $4^{\circ} \mathrm{C}$. After several rinses, the sections were incubated for $1 \mathrm{~h}$, at room temperature, in biotinylated donkey anti-goat (1:1000; Vector Labs, BA-5000). After additional rinses, sections were incubated in avidin-biotin-HRP conjugate (ABC, Vector Labs) (Hsu et al., 1981) for $30 \mathrm{~min}$, followed by nickel-enhanced DAB (Adams, 1981). This resulted in a dark black reaction product (Fig. 1). After several rinses, the section were incubated in anti-GPF (overnight at room temperature), followed by biotinylated donkey anti chicken (1:1500, Jackson ImmunoResearch Laboratories, code 703-065-155), ABC, and unenhanced DAB. This resulted in a brown reaction product (Fig. 1). Finally, the sections were mounted on gelatin-coated slides, dried, and coverslipped.

We adhere to best practices recommended to regularly authenticate biological resources (Collins and Tabak, 2014). We used only validated antibodies that have been repeatedly and successfully used in published 
literature. Control experiments involving preadsorbing or omitting the primary antibody resulted in no specific labeling.

Retrograde labeling. To identify projection neurons in $\mathrm{SpVc}$, we injected rhodamine-labeled fluorescent RetroBeads (LumaFluor) (Katz et al., 1984) into the lateral parabrachial nucleus, guided by stereotaxic coordinates. In brief, 4-week-old GAD-GFP mice were anesthetized with isoflurane and mounted in stereotaxic frame. Two injections of beads (0.7 $\mu \mathrm{l}$, diluted 1:4 in PBS) were made, through a Hamilton syringe, at $4.8 \mathrm{~mm}$ posterior and $1.1 \mathrm{~mm}$ lateral to bregma, at depths of $3.6 \mathrm{~mm}$ and $4.0 \mathrm{~mm}$ ventral to the brain surface. Animals were allowed to recover for at least $48 \mathrm{~h}$ before brain slices were harvested. All injections sites were confirmed post hoc.

Channelrhodopsin-2 (ChR2) injection. To express the light-sensitive protein, ChR2 in corticotrigeminal afferents, we used an AAV5 viral construct that contains the gene for ChR2 and for mCherry (hSynhChR2(H134R)-mCherry). The construct was generously provided by K. Deisseroth (Stanford University), and packaged by the University of North Carolina Vector Core. A Hamilton syringe with a $100-\mu$ m-tip diameter was inserted through a craniotomy, under stereotaxic guidance, and $1 \mu \mathrm{l}$ of the construct was slowly injected into the barrel cortex. In control experiments, we injected a control viral construct lacking the ChR2 gene.

Stimulating electrodes. Rats were anesthetized with isoflurane, placed in a stereotaxic frame, and a craniotomy performed over the barrel cortex. A pair of custom-made, platinum-iridium electrodes $(500 \mathrm{k} \Omega$ ) were implanted in barrel cortex at a depth of $500 \mu \mathrm{m}$ from the pial surface. The distal ends of the electrodes were connected through wires to pins secured to a dental cement cap mounted on the skull. Animals recovered for at least a week before used for behavioral experiments.

In vitro recordings. At least 4 weeks after they were injected with ChR2, the animals were anesthetized with ketamine/xylazine, their brains removed, and horizontal slices (300- $\mu$ m-thick) containing SpVc were prepared, following the method described by Ting et al. (2014). For recordings, slices were placed in an interface chamber and continually perfused $(2 \mathrm{ml} / \mathrm{min})$ with ACSF containing the following (in $\mathrm{mm}$ ): $119 \mathrm{NaCl}, 2.5 \mathrm{KCl}, 1.2 \mathrm{NaH}_{2} \mathrm{PO}_{4}$, $2.4 \mathrm{NaHCO}_{3}, 12.5$ glucose, $2 \mathrm{MgSO}_{4} \cdot 7 \mathrm{H}_{2} \mathrm{O}$, and $2 \mathrm{CaCl}_{2} \cdot 2 \mathrm{H}_{2} \mathrm{O}$.

We obtained whole-cell patch-clamp recordings, in voltage-clamp mode, through pipettes containing the following (in mM): 130 cesium methanesulfonate, 10 HEPES, 1 magnesium chloride, 2.5 ATP-Mg, 0.5 EGTA, and 0.2 GTP-Tris. For recordings in bridge mode, we replaced cesium methanesulfonate with potassium gluconate $(120 \mathrm{~mm})$ and potassium chloride $(10 \mathrm{~mm})$. Impedance of patch electrodes was $4-6 \mathrm{~m} \Omega$. Series resistance $(<40 \mathrm{M} \Omega$, compensated at least $60 \%)$ was monitored throughout the recording, and recordings were discarded if series resistance changed by $>20 \%$. All recordings were obtained at room temperature.

To optically activate ChR2, we collimated blue light through a waterimmersion $40 \times$ microscope objective to achieve whole-field illumination. Light source was a single wavelength $(470 \mathrm{~nm})$ LED system (CoolLED pE-100), controlled through a TTL signal.

We obtained the following agents from RBI-Sigma: CNQX $(20 \mu \mathrm{M})$, D-AP5 $(50 \mu \mathrm{M})$, or from Tocris Bioscience: gabazine $(10 \mu \mathrm{M})$. Drugs were bath-applied to the perfusate.

In vivo recordings. Rats were anesthetized with an intraperitoneal injection of urethane $(1.2 \mathrm{~g} / \mathrm{kg})$, and paralyzed by neuromuscular blockade (pancuronium bromide, $0.03-0.1 \mathrm{mg} / \mathrm{kg}$ ). Animals were artificially ventilated through a tracheal cannula, and core temperature was maintained at $37^{\circ} \mathrm{C}$ with a thermo-regulated heating blanket. Heart rate, $\mathrm{CO}_{2}$ levels, and reflexes were continually monitored. Pancuronium bromide and additional doses of urethane were delivered through a cannula implanted in the jugular vein. We selected urethane because it has no, or negligible, effects on glutamatergic and GABAergic transmission and therefore produces only minimal disruption of signal transmission (Sceniak and Maciver, 2006). The rats were placed in a spinal stereotaxis apparatus, and a small opening made in the bone and dura to expose the brainstem caudal to the cerebellum. Responses of SpVc neurons were obtained by recording single-unit responses through a glass or metal electrode $(<5 \mu \mathrm{m}$ tip diameter). Data were recorded through an AD Instruments analog-todigital converter and analyzed using LabChart 7 software (AD Instru- ments). Time stamps of single units were extracted from raw recordings using dual-threshold discrimination and template matching using the root mean square deviation and fit tolerance.

Wide dynamic range neurons were classified according to their responses to both innocuous and nociceptive mechanical stimuli applied to their receptive fields with an electronic anesthesiometer (IITC Life Science). For quantitative analyses of response magnitudes, stimuli (a single, $2 \mathrm{~ms}$ stimulus pulse) were applied through wires implanted subcutaneously in the buccal region. Once the threshold for activating C-fibers was determined, stimuli were delivered at 3 times threshold.

A craniotomy was performed to place a concentric stimulating electrode in SI cortex, $500 \mu \mathrm{M}$ deep to the pial surface. Stimuli were delivered at 100 to $150 \mu \mathrm{A}, 300 \mathrm{~ms}$ duration, at 50 to $300 \mathrm{~Hz}$.

At the end of the experiment rats were perfused transcardially with aldehydes for histology to identify recording sites.

Grooming behavior. Rats that were implanted with stimulating electrodes were acclimated to the testing environment and to being connected to stimulator wires from the stimulator. Animals were briefly ( $5 \mathrm{~min}$ ) anesthetized with isoflurane (2\%), capsaicin cream (5\%; Professional Arts Pharmacy) was applied to the buccal region, immediately posterior to the vibrissae, and the animal's grooming behavior was monitored and videotaped for $30 \mathrm{~min}$, as previously described (RomeroReyes et al., 2013). In sham-treated rats, the carrier cream (DermaBASE, Perrigo) used to prepare the capsaicin formulation was applied as above. Rats assigned to the stimulation group were electrically stimulated through the SI implanted electrodes $(100 \mu \mathrm{A}, 50 \mathrm{~Hz}$ trains, applied for $5 \mathrm{~s}$ every $10 \mathrm{~s}, 50 \%$ duty cycle) for the duration of the testing. Rats assigned to the sham stimulation group were connected to the stimulation wires, but no stimuli were applied.

Experimental design and statistical analysis. We adhered to accepted standards for rigorous study design and reporting to maximize the reproducibility and translational potential of our findings, as described by Landis et al. (2012) and in ARRIVE (Animal Research: Reporting In Vivo Experiments) Guidelines. Animals were randomly allocated to experimental or control groups, as described by Kim and Shin (2014). In all experiments, the investigators were blinded to animal condition. A coded key of all specimens evaluated was kept and was not shared with the investigators performing the experiments until data analyses were completed. Thus, allocation concealment, blinded conduct of the experiment, and blinded assessment of the outcomes were performed.

For each experiment, we performed a power analysis to estimate the required sample size needed, and exceeded that number in every experiment. For these calculations, we used published information and preliminary data to define the expected means and SDs for each group. In this analysis, we assumed a desired Type I error probability of 0.01 and a power of 0.8

Statistical analyses were performed using Prism 7 (GraphPad Software). We used nonparametric statistics (Mann-Whitney rank-sum or Wilcoxon matched-pair signed rank tests) to compare properties of different classes of neurons recorded in vitro. Nonparametric tests were used also to compare the effects of cortical stimulation on grooming behaviors. Paired $t$ tests were used to compare magnitudes of synaptic responses before and after gabazine application. Paired $t$ tests were used also to compare neuronal activity recorded in vivo before and after cortical stimulation. Multiple comparisons were controlled for, as detailed in each experimental result.

\section{Results}

\section{Anatomy}

To test the prediction that there exists an anatomical substrate for neurons in the mouse spinal trigeminal nucleus caudalis $(\mathrm{SpVc})$ to receive inputs from somatosensory cortex, we injected CTB into the barrel (vibrissae) cortex. We used mice that express GFP in neurons expressing GAD2 (GAD-GFP), to identify a population of GABAergic neurons in SpVc. In histological sections, GAD-GFP somata and dendrites appear brown, due to their DAB reaction product, and were clearly distinguished from CTBlabeled axons that appeared black, due to their nickel-enhanced 


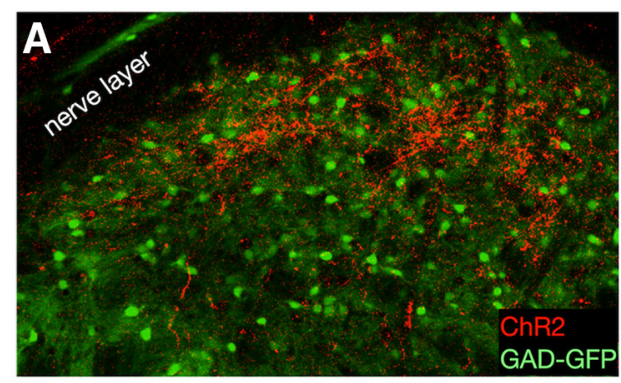

D

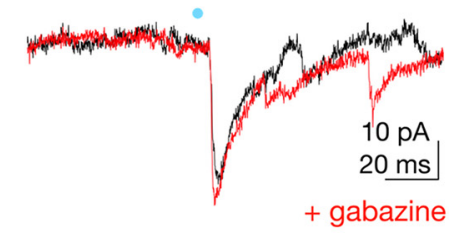

G

Response Latency

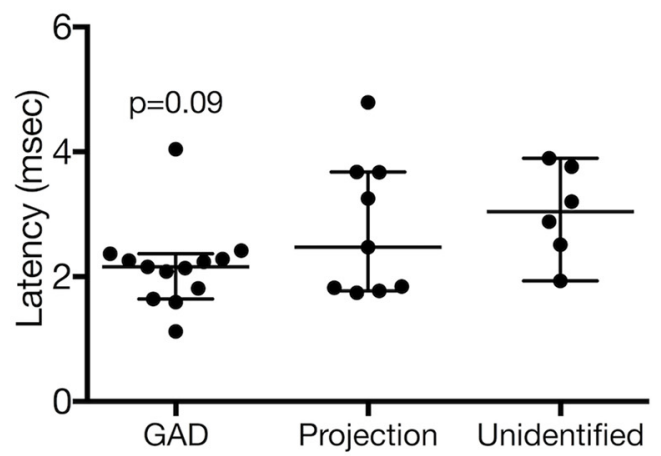

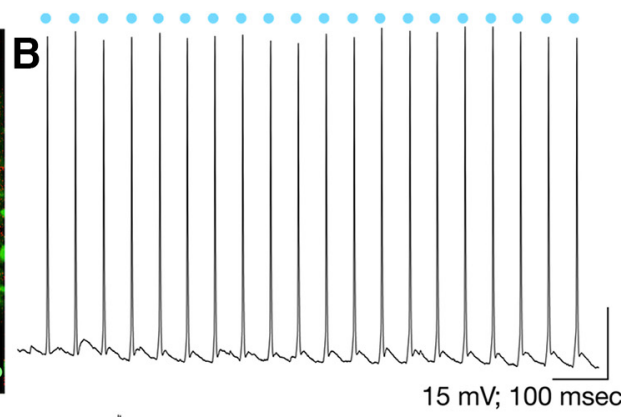

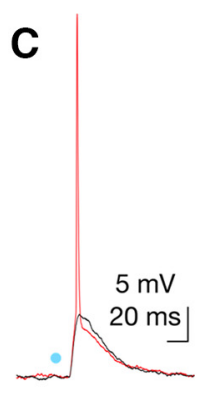

F

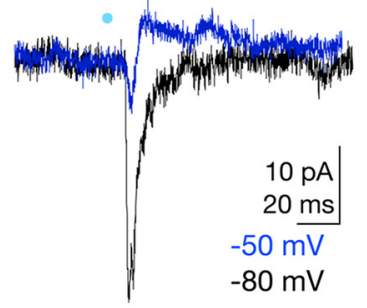

E

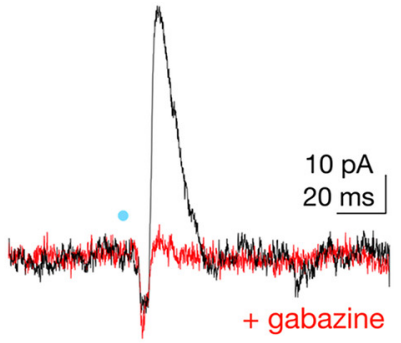

H

Response Magnitude

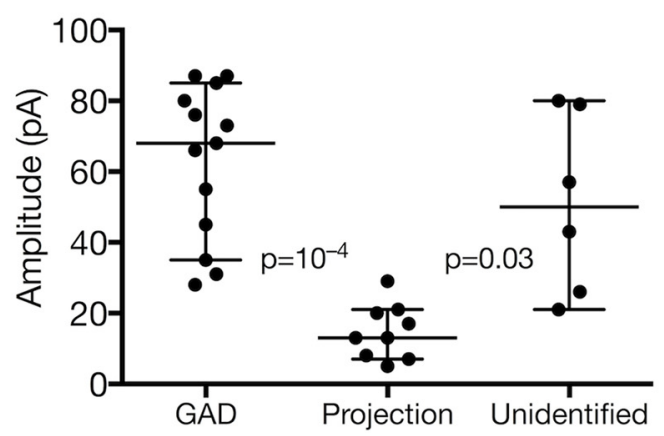

Figure 2. Optogenetic activation of corticotrigeminal inputs to SpVc neurons in vitro. A, Digitized image depicting corticotrigeminal axons expressing mCherry, following anterograde transport of the ChR2-mCherry construct in SI, and GAD-GFP expressing GABAergic neurons in SpVc. "Nerve layer" contains central and peripheral trigeminal nerve axons. B, Brief (0.1 ms) blue-light stimuli (at times indicated by blue circles) entrain a pyramidal neuron in SI that expresses ChR2.C, Light-evoked responses from a GAD-GFP neuron in SpVc, recorded in bridge mode. At lower light intensity (black trace), stimulation of corticotrigeminal input evokes a short latency EPSP. At higher light intensity, an action potential is evoked (red). D, Responses recorded in voltage-clamp ( $-70 \mathrm{mV}$ ) from a GAD-GFP neuron in SpVc. Stimulation of corticotrigeminal inputs evoked an inward current (black) that was not significantly affected by suppressing GABA ${ }_{A}$ receptors with gabazine (red). $E$, Voltage-clamp recording $(-70 \mathrm{mV})$ from an $\mathrm{SpV}$ c neuron that projects to the parabrachial nucleus, in which stimulation evoked a small inward current followed by a large outward current (black trace). The outward current was suppressed by gabazine (red). $\boldsymbol{F}$, Voltage-clamp recording from an unidentified SpV cneuron in which light stimulation evoked an inward current at $-80 \mathrm{mV}$ holding potential (black trace). At $-50 \mathrm{mV}$ (blue), an outward current was revealed. $\mathbf{G}$, Box-and-whisker plots demonstrate that response latency was indistinguishable in recordings from the three neuronal classes. However, response magnitude was significantly lower in projection neurons $(\boldsymbol{H})$.

$\mathrm{DAB}$ reaction product (Fig. 1). Cortical injection sites were restricted to the core of the barrel cortex, identified by its characteristic barrel-like cellular aggregates in layer IV. CTB reaction product was restricted to the cortical gray matter, and did not encroach the underlying white matter.

In $\mathrm{SpVc}$, CTB labeled axons and their varicosities were densely distributed, in particular in the superficial (I-II) and deep (V-VI) laminae of the subnucleus. These labeled corticotrigeminal axons were typically surrounded by a high density of varicosities, presumably axon terminals, particularly along their distal segments. These terminals were often in close apposition to labeled dendrites and somata of GAD-GFP neurons (Fig. 1). Often, a corticotrigeminal axon would run parallel to a GAD-GFP dendrite, with several of the axon's varicosities in apposition to the dendrite. In addition, labeled axon terminals were found in apposition to labeled GAD-GFP somata.

These findings indicate that, as in the rat (Wise and Jones, 1977; Killackey et al., 1989; Ohta and Saeki, 1989; Desbois et al.,
1999; Gojyo et al., 2002; Noseda et al., 2010; Malmierca et al., 2012; Smith et al., 2015; Wang et al., 2015), cortical efferents from mouse primary somatosensory cortex project directly and densely to SpVc. Although it is not possible to determine, with the resolution of light microscopy, if an axonal varicosity in apposition to a postsynaptic element is forming a synapse, these findings suggest the existence of an anatomical substrate for direct corticotrigeminal inputs to inhibitory neurons in SpVc. The following experiments directly test this prediction.

\section{In vitro recordings}

To test the prediction that corticotrigeminal axons synapse with SpVc neurons, we injected, into the barrel cortex of GAD-GFP mice, a viral construct that produces neuronal expression of channelrhodopsin (ChR2) and red fluorescent protein (mCherry). This resulted in robust expression of mCherry within barrel cortex, and within corticotrigeminal axons in SpVc (Fig. 2A). Cortical injections of the viral construct resulted in uptake and 
expression of mCherry within a sphere $\leq 300 \mu \mathrm{m}$ around the injection site (Cruikshank et al., 2010).

Whole-cell patch-clamp recordings from mCherry-expressing neuronal somata in barrel cortex demonstrated that short pulses (0.1-1 ms duration) of blue light produced short latency action potentials in the recorded neurons, and that these can be entrained to stimulus trains of at least $20 \mathrm{~Hz}$ (Fig. 2B). Injection of a control viral construct lacking the ChR2 gene resulted in expression in cortical neurons of mCherry; these mCherry-expressing neurons failed to respond to light stimuli. Because the ChR2 construct cannot transport trans-synaptically, and because there are no direct trigemino-cortical connections that might transport the construct retrogradely, $\mathrm{ChR} 2 \mathrm{in} \mathrm{SpVc}$ is restricted to corticotrigeminal axons and their terminals.

The use of transgenic mice that express GFP exclusively in inhibitory neurons allowed us to target recordings to this class of $\mathrm{SpVc}$ neurons (Fig. 2A). These mice were injected with retrogradely transported fluorescent labeled beads targeted to the parabrachial nucleus (PB; see Materials and Methods), allowing us to target recordings to projection neurons in $\mathrm{SpVc}$.

By optically stimulating corticotrigeminal axons within $\mathrm{SpVc}$, in an in vitro slice preparation, we determined whether SI afferents directly activate $\mathrm{SpV}$ c neurons. We restricted our recordings to neurons in the superficial layers (I-II) of SpVc, as these contained a high density of corticotrigeminal axons and of PBprojecting neurons. We recorded from three groups of neurons: (1) GABAergic neurons expressing GFP; (2) projection neurons, identified by their content of fluorescent latex beads retrogradely transported after injections in PB; and (3) unidentified neurons. Because the expression of $\mathrm{ChR} 2$ can vary between animals, slices, and even different regions in a given slice, it was not possible to reliably determine the percentage of neurons in each group that responded to light stimulation. All light-evoked responses were abolished in the presence of the antagonists of the glutamate receptor antagonists, CNQX $(20 \mu \mathrm{M})$ and APV $(50 \mu \mathrm{M})$.

\section{GAD-GFP neurons}

We recorded from 13 GAD-GFP neurons, from 9 mice, that responded to light stimulation. A representative example is shown in Figure $2 C, D$. Recordings in bridge mode revealed shortlatency postsynaptic potentials evoked by a brief $(1 \mathrm{~ms})$ light stimulus; increasing the light intensity resulted in a suprathreshold response (Fig. $2 C)$. In voltage-clamp $(-70 \mathrm{mV}), 1$-ms-long light pulses evoked a short latency, large inward current (Fig. 2D). The variance in latency of responses recorded from each neuron was relatively low (coefficient of variation $\leq 15 \%$ ), suggesting that these responses were evoked monosynaptically (Berry and Pentreath, 1976). At a holding potential of $-70 \mathrm{mV}$ all responses appeared as inward currents, and often exhibited additional, later components, as depicted in Figure $2 C$, consistent with polysynaptic activation.

The median response latency of GAD-GFP neurons was 2.16 $\mathrm{ms}$ (mean $=2.17 \mathrm{~ms}$; CI 1.76-2.57 ms). Median response magnitude was $68 \mathrm{pA}$ (mean $=61 \mathrm{pA}$; CI 50-76 pA). As described above, application of CNQX and APV abolished these responses, but gabazine $(10 \mu \mathrm{M})$, the $\mathrm{GABA}_{\mathrm{A}}$ receptor antagonist, had no significant effect on the amplitude of these responses $(p \geq 0.5$, paired $t$ tests). These findings suggest that these responses are mediated by glutamate release from corticotrigeminal terminals, and that these responses are not significantly modulated by tonic or feedforward GABAergic inhibition.

\section{Projection neurons}

We recorded from 9 neurons, from 7 mice, that responded to light stimulation; these neurons contained fluorescent beads that were retrogradely transported from the parabrachial nucleus. A representative example is shown in Figure 2E, depicting a biphasic response, a low amplitude, short latency, inward current, followed by a large amplitude outward current. Similar biphasic responses occurred in 7 of the 9 neurons; the remaining two neurons displayed only an inward current. As depicted in Figure $2 E$, the outward component was suppressed by gabazine, confirming that it represents $\mathrm{GABA}_{\mathrm{A}}$ receptor mediated currents. That this $\mathrm{GABA}_{\mathrm{A}}$ mediated current was apparent at a holding potential of $-70 \mathrm{mV}$, a potential at which the driving force for chloride ions is expected to be relatively low, suggests that projection neurons receive potent, perisomatic inputs from GABA synapses. Recordings in bridge mode revealed that light stimulation resulted in postsynaptic potentials, but, in contrast to the inhibitory neurons, in no case were action potentials evoked, even in response to high intensity and long duration light pulses.

The median response latency of projection neurons was $2.47 \mathrm{~ms}$ $($ mean $=2.78 \mathrm{~ms} ;$ CI $1.93-3.64 \mathrm{~ms} ; n=9)$. These latencies were indistinguishable from those of GAD-GFP neurons $(n=13 ; p=$ 0.29, Mann-Whitney rank-sum test $U=42$; Fig. $2 G$ ). As in GADGFP neurons, the response latencies had relatively low variance (coefficient of variation $\leq 18 \%$ ), suggesting that they were generated monosynaptically.

By contrast with response latencies, the magnitude of responses recorded in projection neurons was markedly smaller than those in GAD-GFP neurons $(n=13)$. Median response magnitude of identified projection neurons was $13 \mathrm{pA}(n=9$; mean $=15 \mathrm{pA}$; CI 9-21 pA). Thus, the mean response magnitude of GAD-GFP neurons was, on average, $>4$-fold larger than that of projection neurons ( $p=10^{-4}$, Mann-Whitney $U=1$; Fig. $2 H$ ).

\section{Unidentified neurons}

We recorded also from 6 neurons, from 4 mice, that were labeled with neither beads nor GFP, and, thus, whose phenotype was unknown. These may have included projection neurons that were not labeled, or local inhibitory or excitatory interneurons that do not express GAD2. As depicted in Figure 2F, most of these neurons responded with a single component, an inward current. However, an outward current could be revealed by holding the neurons at a potential more depolarized than the reversal potential for chloride (Fig. $2 F$ ). Thus, these neurons appear to receive direct excitation from corticotrigeminal axons, and a disynaptic inhibition that was more modest than that of projection neurons. As expected from this potentially diverse population, their response magnitudes had a large variance $(\mathrm{CI}=24-77 \mathrm{pA}$; me$\operatorname{dian}=13 \mathrm{pA} ;$ mean $=15 \mathrm{pA})$. Response amplitudes of the three neuronal classes were significantly different $(p=0.0002$; KruskalWallis statistic $=16.98)$; as indicated above, responses recorded from projection neurons were significantly smaller than those from GAD-GFP neurons; they were also smaller than those recorded from unidentified neurons ( $p=0.03$; Kruskal-Wallis multiple comparisons with Dunn's correction)

However, the latency of these responses (median $=3.04$; mean $=3.03 \mathrm{~ms}$; CI $2.24-3.82 \mathrm{~ms}$ ) was indistinguishable from that of the other classes of neurons ( $p=0.09$; Kruskal-Wallis statistic $=4.76$ ).

These findings indicate that corticotrigeminal axons from SI target a mixed population of neurons in $\mathrm{SpVc}$, and that inhibitory neurons receive more potent inputs, resulting in powerful feedforward inhibition of $\mathrm{SpVc}$ projection neurons. 

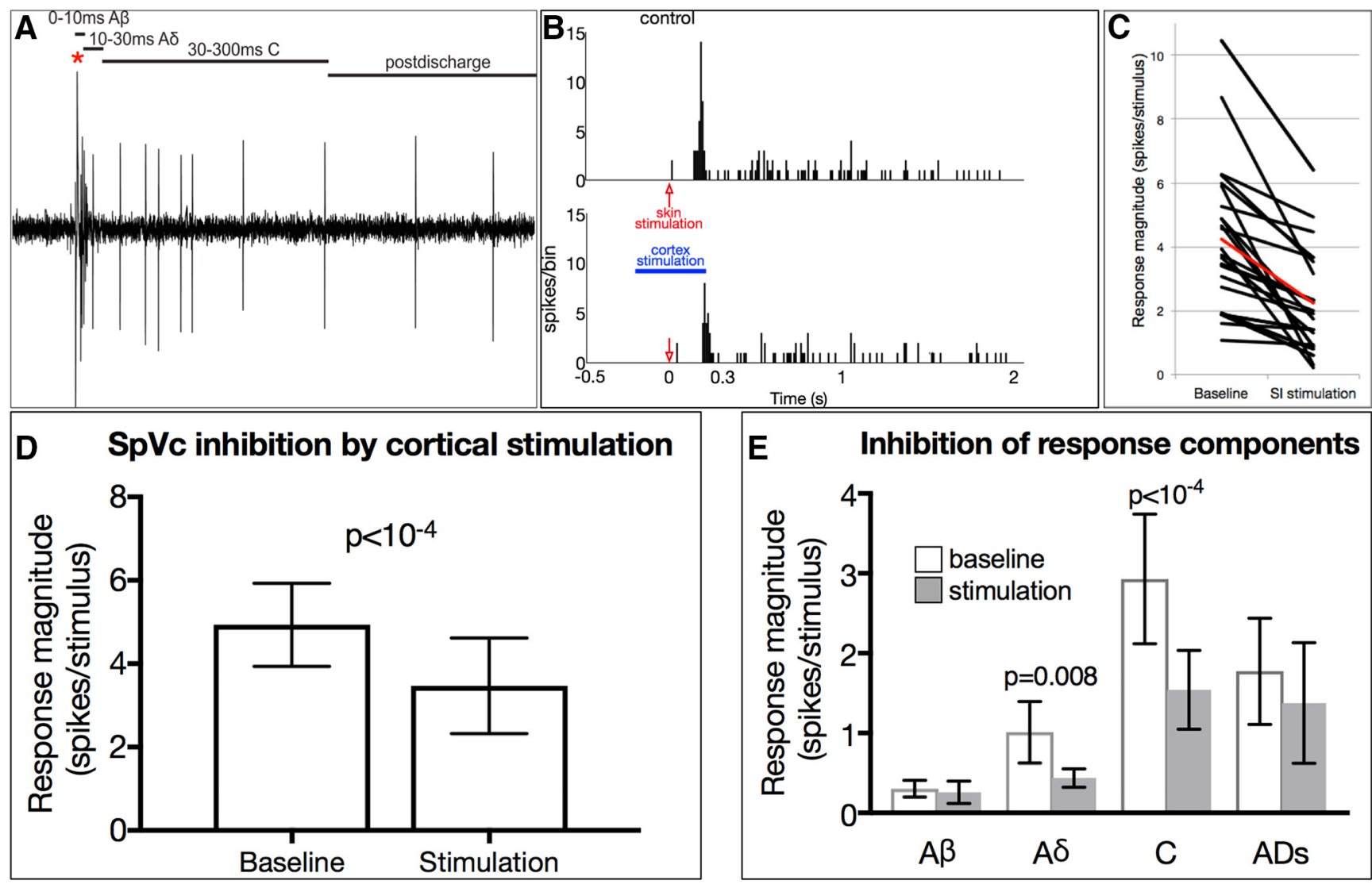

Figure 3. Responses recorded from SpVc neurons in vivo are suppressed by stimulation of $S I$. $A$, Extracellular spikes recorded from a wide dynamic range neuron in $S p V c$ in response to electrical stimulation of the skin. *Stimulus artifact. Response components defined by their latencies are indicated. $\boldsymbol{B}$, Histograms of responses of an SpVc neuron to noxious skin stimulation (at $t=0$; average of 30 stimuli) before (above) and during (below) stimulation of SI. Bin size $=10 \mathrm{~ms}$. C, Changes in response magnitudes (initial $300 \mathrm{~ms}$ of responses) in the $29 \mathrm{SpV}$ ( neurons in which barrel cortex (SI) stimulation had a significant effect on responses to noxious stimuli. Red line indicates the average. $\boldsymbol{D}$, Population means and Cls of response magnitudes before and during $S \mathrm{~S}$ stimulation. $\boldsymbol{E}$, Barrel cortex stimulation had a significant effect only on A-delta and C-fiber response components. AD, Afterdischarge. Significance values reflect comparisons between stimulation and baseline response magnitudes.

\section{In vivo recordings}

To test whether corticotrigeminal inputs can regulate neuronal activity in SpVc, we recorded single units in SpVc of anesthetized rats, before and during electrical stimulation of SI. All recordings were made from wide-dynamic range neurons in laminae $\mathrm{V}$ or VI of SpVc. In preliminary experiments, we compared the effects of stimulating SI at $50 \mathrm{~Hz}$ versus $200 \mathrm{~Hz}$; stimulation intensity was set at $100 \mu \mathrm{A}$, pulse duration at $0.3 \mathrm{~ms}$, and train duration at 300 ms. We averaged, for each neuron, responses to at least 10 noxious skin stimuli without cortical stimulation, and compared these with an average of at least 10 skin stimuli applied with SI stimulation. Response magnitude was calculated during the first $300 \mathrm{~ms}$ following stimulus onset. For each neuron, we defined as threshold for a change in mean response magnitude using paired $t$ tests $(p<0.05)$. Based on this criterion, 29 of 44 neurons (66\%) were inhibited by $50 \mathrm{~Hz}$, whereas 5 of $15(33 \%)$ were inhibited by $200 \mathrm{~Hz}$, a significantly different ratio ( $p=0.04$, Fisher's exact test, two-tailed). Therefore, in all subsequent experiments, we stimulated SI at $50 \mathrm{~Hz}$.

Figure $3 A$ depicts a representative example of spikes recorded from an $\mathrm{SpVc}$ neuron in response to skin stimulation (at $t=0$ ). As in most $\mathrm{SpVc}$ neurons, this cell had a low level of spontaneous activity. The neuron responded robustly to noxious stimulation to the skin through current injection ( $2 \mathrm{~ms}$ duration, $3 \times$ threshold) applied through subcutaneous wires. As depicted in Figure $3 A$, and as typical for $\mathrm{SpVc}$ neurons, this response had several components, including a postdischarge that outlasted the stimulus. Figure $3 B$ shows representative example of changes in neuronal activity of an SpVc neuron in response to SI stimulation. Stimulation of SI, at $50 \mathrm{~Hz}$, had no significant effect on the already low level of spontaneous firing in this neuron. However, when skin stimulation was coupled with a train of stimuli applied to SI, the magnitude of the response to skin stimulation was substantially reduced.

SI stimulation significantly ( $p \leq 0.05$, paired $t$ tests) decreased the magnitude of responses to skin stimulation in 29 of $44 \mathrm{SpVc}$ neurons tested (66\%; Fig. $3 C)$. There was no significant change in the response magnitude of the remaining 15 neurons. Averaging all 44 neurons, including those that did not exhibit a significant effect to cortical stimulation, revealed that response magnitude decreased by SI stimulation from 4.94 spikes/stimulus (median $=$ 3.83, CI 3.9-5.9) to 3.47 spikes/stimulus (median $=2.33$, CI $=$ $2.3-4.9)$. This decrease was statistically significant $(p<0.0001$; $t_{(43)}=5.008, t$ test; Fig. $3 D$ ).

Five of the neurons described above responded with antidromic spikes to stimulation of the parabrachial nucleus, suggesting that they are projection neurons. The responses of all five neurons to skin stimulation were significantly inhibited by SI stimulation. The identity of the remaining 24 neurons is unknown, although many of them are likely to be projection neurons because our extracellular recording electrodes are biased toward recording spikes generated by larger neurons, such as 
projection neurons in SpVc (Cechetto et al., 1985; Haring et al., 1990; Haenggeli et al., 2005).

As depicted in Figure $3 A$, and consistent with previous descriptions of responses of SpVc neurons (Urch and Dickenson, 2003; Bannister et al., 2014; Leith et al., 2014), responses to skin stimulation had several temporal components. We classified these temporal components according to previously established conduction velocities of primary afferents (Urch and Dickenson, 2003) as follows: $0-10 \mathrm{~ms}$ after stimulus was defined as an $\mathrm{A} \beta$ response; $10-30 \mathrm{~ms}$ as $\mathrm{A} \delta ; 30-300 \mathrm{~ms}$ as $\mathrm{C}$-fiber; and $300-2000$ $\mathrm{ms}$ as postdischarge (or afterdischage). Although this classification is based on analyses of spinal neurons, trigeminal neurons display a similar range of conduction velocities and axonal diameters as that of spinal neurons, suggesting that this classification may be applicable to trigeminal axons (Falls and Alban, 1986; Bouhassira et al., 1987; Tsuboi et al., 2004). This allowed us to determine whether SI stimulation affected each of these response components. These analyses revealed that only the A $\delta$ responses (median reduced by 27\%) and the C-fiber responses (44\% inhibition) were significantly inhibited by SI stimulation (Fig. $3 E$ ). A $\delta$ response reduced from $1.01 \pm 0.37$ spikes/stimulus (mean $\pm \mathrm{CI}$ ) to $0.44 \pm 0.11$ spikes/stimulus $\left(p=0.008, t_{(28)}=2.866\right.$, paired $t$ test) and C-fiber responses were reduced from $2.93 \pm 0.78$ spikes/ stimulus to $1.54 \pm 0.47$ spikes/stimulus $\left(p<10^{-4}, t_{(28)}=6.165\right.$, paired $t$ test). Thus, SI stimulation preferentially affected responses mediated by nociceptive afferents.

\section{Behavior}

The inhibition of responses to noxious stimuli by SI stimulation predicts that cortical stimulation will suppress nociceptive behaviors. To test this prediction, we tested the ability of cortical stimulation to affect grooming behavior evoked by applying capsaicin to the buccal region, immediately posterior to the vibrissa pad (see Materials and Methods). We monitored and videotaped the rats' behaviors for $30 \mathrm{~min}$ after applying 5\% capsaicin cream. We scored the total duration of three grooming behaviors: (1) rubbing of the face with the forepaws, (2) rubbing the lower lip and cheek against the cage floor, and (3) scratching the face with the hindpaw (Romero-Reyes et al., 2013). We compared the behaviors of rats in which SI was stimulated $(100 \mu \mathrm{A}, 0.3 \mathrm{~ms}$ pulse duration, $50 \mathrm{~Hz}$ trains of $300 \mathrm{~ms}$ duration, $5 \mathrm{~s}$ duty cycle) for the duration of the testing ( $30 \mathrm{~min}$ ), with behaviors of rats in which the implanted SI electrodes were connected to the stimulator, but no stimulation was delivered. To account for innate tendency to groom, for each rat we normalized grooming behavior duration to the duration of grooming recorded for $30 \mathrm{~min}$ before capsaicin was applied. There was no significant difference ( $p=0.7$, MannWhitney $U=12 ; n=5$ and 4 rats) in baseline grooming between the stimulated (median $=5.8 \mathrm{~s} ; 95 \%$ CI $0.9-10.0$ ) or the sham animals (median $=6.6 \mathrm{~s} ; 95 \% \mathrm{CI}-0.3$ to 13.4 ).

SI stimulation significantly reduced the duration of grooming behavior ( $p=0.03$, Wilcoxon matched-pair signed rank test, $\mathrm{W}=-21, r=0.03$; Fig. 4). Normalized grooming duration decreased from a median of $4.6($ mean $=5.1, \mathrm{CI}=3.2-7.0)$ to a median of 0.7 (mean $=0.8, \mathrm{CI}=0.2-1.5)$. By contrast, grooming behavior following application of sham cream, in a different group of rats, was not significantly affected by cortical stimulation: Normalized medians before and after stimulation were 0.13 and 4.87 , respectively ( $\mathrm{W}=10, p=0.13, r=0.97, n=8)$. In 2 of the animals in the sham-cream group, SI stimulation appeared to have induced increased grooming, increasing the variance in this metric, without significantly affecting the statistical conclusions.

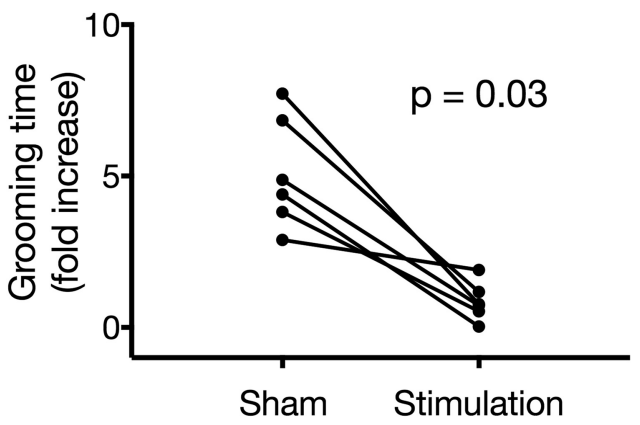

Figure 4. Stimulation of SI significantly reduced the duration of grooming behaviors evoked by capsaicin application to the face. $N=9$ rats ( 5 stimulated; 4 sham).

These findings suggest that cortical stimulation significantly reduced pain perception.

\section{Discussion}

Our goal was to test the hypothesis that the corticotrigeminal pathway modulates pain perception by activating inhibitory neurons in $\mathrm{SpVc}$, thus generating feedforward inhibition of trigemino-projection cells. In support of this hypothesis, we found: (1) corticotrigeminal axons form dense terminal plexi around GABA neurons in SpVc; (2) stimulation of corticotrigeminal axons in vitro produces strong excitation in inhibitory neurons of SpVc, and feedforward inhibition of projections and excitatory neurons in this nucleus; (3) stimulation of SI, a major source of corticotrigeminal axons, suppresses nociceptive responses in SpVc; (4) and stimulation of SI produces analgesia.

\section{An anatomical substrate for cortical inputs to inhibitory neurons in SpVc}

Anatomical tract tracing revealed that corticotrigeminal axons terminate densely in SpVc of mice (Fig. 1). This is, to our knowledge, the first demonstration of this pathway in the mouse, and it confirms previous findings in rats (Wise and Jones, 1977; Wise et al., 1979; Killackey et al., 1989; Ohta and Saeki, 1989; Ohta et al., 1989; Desbois et al., 1999; Gojyo et al., 2002; Noseda et al., 2010; Malmierca et al., 2012; Smith et al., 2015; Wang et al., 2015), cats (Brodal et al., 1956; Dunn and Tolbert, 1982; Tashiro et al., 1983; Tolbert et al., 1984; McHaffie et al., 1988), and humans (Nordstrom et al., 1999; Butler et al., 2001; Jaberzadeh et al., 2008; Ortu et al., 2008).

We found that corticotrigeminal axons from SI form multiple varicosities abutting the somata and dendrites of GABAergic neurons in SpVc. Although it is not possible to ascertain, at the light microscopic level, whether these varicosities form synapses, available evidence from quantitative analyses in SI cortex suggest that essentially all varicosities form synapses, that some form multiple synapses, and that synapses can also be formed by axonal shafts (White et al., 2004). Thus, our light microscopy data likely underestimate the innervation of GABA neurons in SpVc by corticotrigeminal afferents. Further, corticotrigeminal axons likely provide inputs to other inhibitory neurons not examined here, including GABAergic neurons that did not express GAD2GFP, and the numerous glycine-containing neurons in this nucleus (Avendano et al., 2005). Similarly, corticotrigeminal axons may directly innervate excitatory neurons in $\mathrm{SpVc}$, an anatomical pattern we did not study here. 
These findings suggest that corticotrigeminal axons provide dense and potent inputs to $\mathrm{SpVc}$, including to the inhibitory neurons of this nucleus. These inputs provide an anatomical substrate for feedforward inhibition of $\mathrm{SpVc}$ neurons by the excitatory corticotrigeminal afferents.

\section{Cortical inputs excite inhibitory $\mathrm{SpVc}$ neurons}

Consistent with a feedforward circuit, our electrophysiological findings indicate that corticotrigeminal inputs activate inhibitory neurons in SpVc. We show that optogenetic activation of corticotrigeminal axons evokes stronger synaptic currents in inhibitory neurons, compared with their excitatory counterparts (Fig. 2). We recognize that comparisons of synaptic efficacies based on optogenetic data are subject to misinterpretation because of potential differences in the expression of ChR2 in different animals or different brain slices. However, we saw no qualitative difference in expression in slices from which inhibitory or excitatory neurons were recorded, and we see no reason why such differences would occur. Further, our whole-cell recording data show that corticotrigeminal inputs evoke, in inhibitory neurons, a strong monosynaptic excitatory response, whereas in projection neurons they evoke weak excitation followed by strong inhibition. These synaptic patterns are consistent with the postulated feedforward inhibitory circuit in SpVc. This feedforward inhibition has been reported to potently regulate the activity of projection neurons in this nucleus (Jacquin et al., 1989).

\section{Cortical stimulation suppresses neuronal responses in $\mathrm{SpVc}$}

Also consistent with this postulated circuit is our finding that stimulation of SI results in suppression of suprathreshold responses of $\mathrm{SpVc}$ evoked by nociceptive inputs (Fig. 3). At least some of the neurons we recorded from were projection cells, as evidenced by their antidromic activation from the parabrachial nucleus. We suspect that many of the other recorded neurons were also projection cells because our recording electrodes are biased toward recording from these larger neurons and because we did not observe suprathreshold activation of neurons by SI stimulation, as expected for inhibitory neurons (Fig. 3C).

We recognize that our slice recordings were made from neurons in the superficial layers of $\mathrm{SpVc}$, whereas in vivo recordings were from neurons in deeper layers, due to the relative instability of in vivo recordings from more superficial layers. These differences do not affect our interpretations or conclusions: The in vitro recordings aimed to determine whether cortical inputs directly modulate neurons in the superficial layers, the termination site of nociceptive afferents (Basbaum et al., 2009; Braz et al., 2014). The in vivo recordings aimed to determine whether outputs from $\mathrm{SpV}$ c to downstream structures are affected by cortical stimulation. Nociceptive activation of projection neurons in $\mathrm{SpVc}$ is thought to require inputs from these interneurons in the superficial layers (Wang et al., 2013; Braz et al., 2014). Therefore, our findings suggest that cortical inputs suppress nociceptive responses of superficial neurons, resulting in reduced activation of projection neurons that reside in both superficial and deep SpVc. We recognize, however, that our findings do not directly demonstrate feedforward inhibition from superficial to deep layers of $\mathrm{SpVc}$, and that this circuitry is only inferred from our results.

Our findings are consistent with those of Malmierca et al. $(2012,2014)$ who reported that SI stimulation $(50 \mathrm{~Hz})$ suppresses nociceptive responses recorded from $\mathrm{SpVc}$ of rats, and that these effects are blocked by antagonists of $\mathrm{GABA}_{\mathrm{A}}$ or glycine receptors. These findings are also consistent with a report that chemically evoked cortical spreading depression involving SI can suppress responses of SpVc neurons (Noseda et al., 2010). In contrast, Gojyo et al. (2002) reported that lower frequency stimulation $(10 \mathrm{~Hz})$ of SI had no effect on formalin-induced changes in immediate early genes expressed by SpVc neurons.

\section{Cortical stimulation produces hypoalgesia}

The ability of corticotrigeminal inputs to activate feedforward inhibition in $\mathrm{SpVc}$ suggests that these inputs may alleviate pain perception, a prediction supported by our findings (Fig. 4). Together, the present findings support the hypothesis that corticotrigeminal inputs to $\mathrm{SpVc}$ engage feedforward inhibition, thereby suppressing the responses of neurons in this nucleus to nociceptive inputs, and producing hypoalgesia.

\section{Functional implications}

Many conditions of chronic pain are thought to result from disinhibition of dorsal horn (including medullary dorsal horn, or, $\mathrm{SpVc}$ ) neurons (for review, see Prescott, 2015). The ability of corticotrigeminal inputs to inhibit $\mathrm{SpVc}$ may provide a potential approach to rekindle the inhibition compromised in chronic pain conditions. Indeed, a promising approach for treating chronic pain involves direct stimulation of the neocortex (Garcia-Larrea and Peyron, 2007; Jiang et al., 2014) through subdural electrodes, or, noninvasively using transcranial magnetic stimulation (Pridmore and Oberoi, 2000; Pridmore et al., 2005).

Clinical studies on effects of neocortex stimulation have focused primarily on the motor cortex as a target because of reports suggesting that stimulating the somatosensory cortex may not alleviate pain (Tsubokawa et al., 1993; Saitoh et al., 2000). However, these studies involved only a small number of subjects, and the efficacy of SI stimulation was not systematically studied. Indeed, SI stimulation has been shown to inhibit the activity of dorsal horn neurons in rats (Senapati et al., 2005), cats (Namba and Nishimoto, 1988), and monkeys (Yezierski et al., 1983), and to ameliorate pain in animals and humans (Canavero and Bonicalzi, 2002; Canavero et al., 2002, 2003; Lee et al., 2017).

Although motor cortex stimulation provides relief to some patients, the efficacy of this approach remains relatively low and inconsistent (Canavero and Bonicalzi, 2002; Garcia-Larrea and Peyron, 2007; Lima and Fregni, 2008). Key to improving these approaches is increased knowledge of the most efficacious cortical stimulation sites and the fundamental neural mechanisms that mediate cortical regulation of pain (O'Connell et al., 2014). The present findings may provide such knowledge.

\section{References}

Adams JC (1981) Heavy metal intensification of DAB-based HRP reaction product. J Histochem Cytochem 29:775. CrossRef Medline

Apkarian AV, Bushnell MC, Treede RD, Zubieta JK (2005) Human brain mechanisms of pain perception and regulation in health and disease. Eur J Pain 9:463-484. CrossRef Medline

Avendano C, Machin R, Bermejo PE, Lagares A (2005) Neuron numbers in the sensory trigeminal nuclei of the rat: A GABA- and glycine-immunocytochemical and stereological analysis. J Comp Neurol 493:538-553. CrossRef Medline

Bannister K, Lee YS, Goncalves L, Porreca F, Lai J, Dickenson AH (2014) Neuropathic plasticity in the opioid and non-opioid actions of dynorphin A fragments and their interactions with bradykinin B2 receptors on neuronal activity in the rat spinal cord. Neuropharmacology 85:375-383. CrossRef Medline

Basbaum AI, Bautista DM, Scherrer G, Julius D (2009) Cellular and molecular mechanisms of pain. Cell 139:267-284. CrossRef Medline

Berry MS, Pentreath VW (1976) Criteria for distinguishing between monosynaptic and polysynaptic transmission. Brain Res 105:1-20. CrossRef Medline

Bouhassira D, Le Bars D, Villanueva L (1987) Heterotopic activation of A 
delta and $\mathrm{C}$ fibres triggers inhibition of trigeminal and spinal convergent neurones in the rat. J Physiol 389:301-317. CrossRef Medline

Braz J, Solorzano C, Wang X, Basbaum AI (2014) Transmitting pain and itch messages: a contemporary view of the spinal cord circuits that generate gate control. Neuron 82:522-536. CrossRef Medline

Brodal A, Szabo T, Torvik A (1956) Corticofugal fibers to sensory trigeminal nuclei and nucleus of solitary tract: an experimental study in the cat. J Comp Neurol 106:527-555. CrossRef Medline

Bushnell MC, Ceko M, Low LA (2013) Cognitive and emotional control of pain and its disruption in chronic pain. Nat Rev Neurosci 14:502-511. CrossRef Medline

Butler SL, Miles TS, Thompson PD, Nordstrom MA (2001) Task-dependent control of human masseter muscles from ipsilateral and contralateral motor cortex. Exp Brain Res 137:65-70. CrossRef Medline

Canavero S, Bonicalzi V (2002) Therapeutic extradural cortical stimulation for central and neuropathic pain: a review. Clin J Pain 18:48-55. CrossRef Medline

Canavero S, Bonicalzi V, Dotta M, Vighetti S, Asteggiano G, Cocito D (2002) Transcranial magnetic cortical stimulation relieves central pain. Stereotact Funct Neurosurg 78:192-196. Medline

Canavero S, Bonicalzi V, Dotta M, Vighetti S, Asteggiano G (2003) Low-rate repetitive TMS allays central pain. Neurol Res 25:151-152. CrossRef Medline

Cechetto DF, Standaert DG, Saper CB (1985) Spinal and trigeminal dorsal horn projections to the parabrachial nucleus in the rat. J Comp Neurol 240:153-160. CrossRef Medline

Collins FS, Tabak LA (2014) Policy: NIH plans to enhance reproducibility. Nature 505:612-613. CrossRef Medline

Cruikshank SJ, Urabe H, Nurmikko AV, Connors BW (2010) Pathwayspecific feedforward circuits between thalamus and neocortex revealed by selective optical stimulation of axons. Neuron 65:230-245. CrossRef Medline

Darian-Smith I, Yokota T (1966) Corticofugal effects on different neuron types within the cat's brain stem activated by tactile stimulation of the face. J Neurophysiol 29:185-206. Medline

Desbois C, Le Bars D, Villanueva L (1999) Organization of cortical projections to the medullary subnucleus reticularis dorsalis: a retrograde and anterograde tracing study in the rat. J Comp Neurol 410:178-196. CrossRef Medline

Dubner R, Ren K (1999) Endogenous mechanisms of sensory modulation. Pain Suppl 6:S45-S53. Medline

Dubner R, Ren K (2004) Brainstem mechanisms of persistent pain following injury. J Orofac Pain 18:299-305. Medline

Dunn RC Jr, Tolbert DL (1982) The corticotrigeminal projection in the cat: a study of the organization of cortical projections to the spinal trigeminal nucleus. Brain Res 240:13-25. CrossRef Medline

Falls WM, Alban MM (1986) Morphology and synaptic connections of small myelinated primary trigeminal axons arborizing among neurons in the border zone of rat trigeminal nucleus oralis. Somatosens Res 4:97110. CrossRef Medline

Fields HL (2000) Pain modulation: expectation, opioid analgesia and virtual pain. Prog Brain Res 122:245-253. CrossRef Medline

Furuta T, Urbain N, Kaneko T, Deschênes M (2010) Corticofugal control of vibrissa-sensitive neurons in the interpolaris nucleus of the trigeminal complex. J Neurosci 30:1832-1838. CrossRef Medline

Garcia-Larrea L, Peyron R (2007) Motor cortex stimulation for neuropathic pain: from phenomenology to mechanisms. Neuroimage 37 [Suppl 1]: S71-S79.

Gojyo F, Sugiyo S, Kuroda R, Kawabata A, Varathan V, Shigenaga Y, Takemura M (2002) Effects of somatosensory cortical stimulation on expression of c-Fos in rat medullary dorsal horn in response to formalin-induced noxious stimulation. J Neurosci Res 68:479-488. CrossRef Medline

Haenggeli CA, Pongstaporn T, Doucet JR, Ryugo DK (2005) Projections from the spinal trigeminal nucleus to the cochlear nucleus in the rat. J Comp Neurol 484:191-205. CrossRef Medline

Haring JH, Henderson TA, Jacquin MF (1990) Principalis- or parabrachialprojecting spinal trigeminal neurons do not stain for GABA or GAD. Somatosens Mot Res 7:391-397. CrossRef Medline

Hattox AM, Nelson SB (2007) Layer V neurons in mouse cortex projecting to different targets have distinct physiological properties. J Neurophysiol 98:3330-3340. CrossRef Medline

Heinricher MM, Tavares I, Leith JL, Lumb BM (2009) Descending control of nociception: Specificity, recruitment and plasticity. Brain Res Rev 60: 214-225. CrossRef Medline

Hernandez-Peon R, Hagbarth KE (1955) Interaction between afferent and cortically induced reticular responses. J Neurophysiol 18:44-55. Medline

Hsu SM, Soban E (1982) Color modification of diaminobenzidine (DAB) precipitation by metallic ions and its application for double immunohistochemistry. J Histochem Cytochem 30:1079-1082. CrossRef Medline

Hsu SM, Raine L, Fanger H (1981) Use of avidin-biotin-peroxidase complex $(\mathrm{ABC})$ in immunoperoxidase techniques: a comparison between $\mathrm{ABC}$ and unlabeled antibody (PAP) procedures. J Histochem Cytochem 29:577-580. CrossRef Medline

Jaberzadeh S, Sakuma S, Zoghi M, Miles TS, Nordstrom MA (2008) Focal transcranial magnetic stimulation of motor cortex evokes bilateral and symmetrical silent periods in human masseter muscles. Clin Neurophysiol 119:693-703. CrossRef Medline

Jacquin MF, Golden J, Rhoades RW (1989) Structure-function relationships in rat brainstem subnucleus interpolaris: III. Local circuit neurons. J Comp Neurol 282:24-44. CrossRef Medline

Jiang L, Ji Y, Voulalas PJ, Keaser M, Xu S, Gullapalli RP, Greenspan J, Masri R (2014) Motor cortex stimulation suppresses cortical responses to noxious hindpaw stimulation after spinal cord lesion in rats. Brain Stimul 7:182-189. CrossRef Medline

Katz LC, Burkhalter A, Dreyer WJ (1984) Fluorescent latex microspheres as a retrograde neuronal marker for in vivo and in vitro studies of visual cortex. Nature 310:498-500. CrossRef Medline

Killackey HP, Koralek KA, Chiaia NL, Rhodes RW (1989) Laminar and areal differences in the origin of the subcortical projection neurons of the rat somatosensory cortex. J Comp Neurol 282:428-445. CrossRef Medline

Kim J, Shin W (2014) How to do random allocation (randomization). Clin Orthop Surg 6:103-109. CrossRef Medline

Landis SC, Amara SG, Asadullah K, Austin CP, Blumenstein R, Bradley EW, Crystal RG, Darnell RB, Ferrante RJ, Fillit H, Finkelstein R, Fisher M, Gendelman HE, Golub RM, Goudreau JL, Gross RA, Gubitz AK, Hesterlee SE, Howells DW, Huguenard J, et al. (2012) A call for transparent reporting to optimize the predictive value of preclinical research. Nature 490:187-191. CrossRef Medline

Lee S, Hwang E, Lee D, Choi JH (2017) Pulse-train stimulation of primary somatosensory cortex blocks pain perception in tail clip test. Exp Neurobiol 26:90-96. CrossRef Medline

Leith JL, Wilson AW, You HJ, Lumb BM, Donaldson LF (2014) Periaqueductal grey cyclooxygenase-dependent facilitation of C-nociceptive drive and encoding in dorsal horn neurons in the rat. J Physiol 592:5093-5107. CrossRef Medline

Lima MC, Fregni F (2008) Motor cortex stimulation for chronic pain: systematic review and meta-analysis of the literature. Neurology 70:2329 2337. CrossRef Medline

López-Bendito G, Sturgess K, Erdélyi F, Szabó G, Molnár Z, Paulsen O (2004) Preferential origin and layer destination of GAD65-GFP cortical interneurons. Cereb Cortex 14:1122-1133. CrossRef Medline

Malmierca E, Martin YB, Nuñez A (2012) Inhibitory control of nociceptive responses of trigeminal spinal nucleus cells by somatosensory corticofugal projection in rat. Neuroscience 221:115-124. CrossRef Medline

Malmierca E, Chaves-Coira I, Rodrigo-Angulo M, Nuñez A (2014) Corticofugal projections induce long-lasting effects on somatosensory responses in the trigeminal complex of the rat. Front Syst Neurosci 8:100. CrossRef Medline

McHaffie JG, Kruger L, Clemo HR, Stein BE (1988) Corticothalamic and corticotectal somatosensory projections from the anterior ectosylvian sulcus (SIV cortex) in neonatal cats: an anatomical demonstration with HRP and ${ }^{3} \mathrm{H}$-leucine. J Comp Neurol 274:115-126. CrossRef Medline

Namba S, Nishimoto A (1988) Stimulation of internal capsule, thalamic sensory nucleus (VPM) and cerebral cortex inhibited deafferentation hyperactivity provoked after gasserian ganglionectomy in cat. Acta Neurochir Suppl (Wien) 42:243-247. Medline

Nordstrom MA, Miles TS, Gooden BR, Butler SL, Ridding MC, Thompson PD (1999) Motor cortical control of human masticatory muscles. Prog Brain Res 123:203-214. CrossRef Medline

Noseda R, Constandil L, Bourgeais L, Chalus M, Villanueva L (2010) Changes of meningeal excitability mediated by corticotrigeminal networks: a link for the endogenous modulation of migraine pain. J Neurosci 30:14420-14429. CrossRef Medline

O'Connell NE, Wand BM, Marston L, Spencer S, Desouza LH (2014) Non- 
invasive brain stimulation techniques for chronic pain. Cochrane Database Syst Rev CD008208.

Ohta M, Saeki K (1989) Corticotrigeminal motor pathway in the rat: I. Antidromic activation. Comp Biochem Physiol A Comp Physiol 94:99-104. CrossRef Medline

Ohta M, Ishizuka S, Saeki K (1989) Corticotrigeminal motor pathway in the rat: II. Anterio- and retrograde HRP labeling. Comp Biochem Physiol A Comp Physiol 94:405-414. CrossRef Medline

Ortu E, Deriu F, Suppa A, Giaconi E, Tolu E, Rothwell JC (2008) Intracortical modulation of cortical-bulbar responses for the masseter muscle. J Physiol 586:3385-3404. CrossRef Medline

Paxinos G, Franklin KB (2004) The mouse brain in stereotaxic coordinates. Amsterdam: Elsevier Academic.

Paxinos, G, Watson, C (2007) The rat brain in stereotaxic coordinates. Amsterdam: Elsevier Academic.

Prescott SA (2015) Synaptic inhibition and disinhibition in the spinal dorsal horn. Prog Mol Biol Transl Sci 131:359-383. CrossRef Medline

Pridmore S, Oberoi G (2000) Transcranial magnetic stimulation applications and potential use in chronic pain: studies in waiting. J Neurol Sci 182:1-4. CrossRef Medline

Pridmore S, Oberoi G, Marcolin M, George M (2005) Transcranial magnetic stimulation and chronic pain: current status. Australas Psychiatry 13:258-265. CrossRef Medline

Romero-Reyes M, Akerman S, Nguyen E, Vijjeswarapu A, Hom B, Dong HW, Charles AC (2013) Spontaneous behavioral responses in the orofacial region: a model of trigeminal pain in mouse. Headache 53:137-151. CrossRef Medline

Saitoh Y, Shibata M, Hirano S, Hirata M, Mashimo T, Yoshimine T (2000) Motor cortex stimulation for central and peripheral deafferentation pain: report of eight cases. J Neurosurg 92:150-155. CrossRef Medline

Sceniak MP, Maciver MB (2006) Cellular actions of urethane on rat visual cortical neurons in vitro. J Neurophysiol 95:3865-3874. CrossRef Medline

Senapati AK, Huntington PJ, LaGraize SC, Wilson HD, Fuchs PN, Peng YB (2005) Electrical stimulation of the primary somatosensory cortex inhibits spinal dorsal horn neuron activity. Brain Res 1057:134-140. CrossRef Medline

Smith JB, Watson GD, Alloway KD, Schwarz C, Chakrabarti S (2015) Corticofugal projection patterns of whisker sensorimotor cortex to the sensory trigeminal nuclei. Front Neural Circuits 9:53. CrossRef Medline

Tashiro T, Matsuyama T, Higo S (1983) Distribution of cells of origin of the corticotrigeminal projections to the nucleus caudalis of the spinal trigeminal complex in the cat: a horseradish peroxidase (HRP) study. Exp Neurol 80:178-185. CrossRef Medline
Ting JT, Daigle TL, Chen Q, Feng G (2014) Acute brain slice methods for adult and aging animals: application of targeted patch clamp analysis and optogenetics. Methods Mol Biol 1183:221-242. CrossRef Medline

Tolbert DL, Dunn RC Jr, Vogler GA (1984) The postnatal development of corticotrigeminal projections in the cat. J Comp Neurol 228:478-490. CrossRef Medline

Tracey I, Mantyh PW (2007) The cerebral signature for pain perception and its modulation. Neuron 55:377-391. CrossRef Medline

Tsuboi Y, Takeda M, Tanimoto T, Ikeda M, Matsumoto S, Kitagawa J, Teramoto K, Simizu K, Yamazaki Y, Shima A, Ren K, Iwata K (2004) Alteration of the second branch of the trigeminal nerve activity following inferior alveolar nerve transection in rats. Pain 111:323-334. CrossRef Medline

Tsubokawa T, Katayama Y, Yamamoto T, Hirayama T, Koyama S (1993) Chronic motor cortex stimulation in patients with thalamic pain. J Neurosurg 78:393-401. CrossRef Medline

Urch CE, Dickenson AH (2003) In vivo single unit extracellular recordings from spinal cord neurones of rats. Brain Res Brain Res Protoc 12:26-34. CrossRef Medline

Villemure C, Bushnell MC (2002) Cognitive modulation of pain: how do attention and emotion influence pain processing? Pain 95:195-199. CrossRef Medline

Wang J, Li ZH, Feng B, Zhang T, Zhang H, Li H, Chen T, Cui J, Zang WD, Li YQ (2015) Corticotrigeminal projections from the insular cortex to the trigeminal caudal subnucleus regulate orofacial pain after nerve injury via extracellular signal-regulated kinase activation in insular cortex neurons. Front Cell Neurosci 9:493. CrossRef Medline

Wang X, Zhang J, Eberhart D, Urban R, Meda K, Solorzano C, Yamanaka H, Rice D, Basbaum AI (2013) Excitatory superficial dorsal horn interneurons are functionally heterogeneous and required for the full behavioral expression of pain and itch. Neuron 78:312-324. CrossRef Medline

White EL, Weinfeld E, Lev DL (2004) Quantitative analysis of synaptic distribution along thalamocortical axons in adult mouse barrels. J Comp Neurol 479:56-69. CrossRef Medline

Wise SP, Jones EG (1977) Cells of origin and terminal distribution of descending projections of the rat somatic sensory cortex. J Comp Neurol 175:129-157. CrossRef Medline

Wise SP, Murray EA, Coulter JD (1979) Somatotopic organization of corticospinal and corticotrigeminal neurons in the rat. Neuroscience 4:65-78. CrossRef Medline

Yezierski RP, Gerhart KD, Schrock BJ, Willis WD (1983) A further examination of effects of cortical stimulation on primate spinothalamic tract cells. J Neurophysiol 49:424-441. Medline 